Revista de
Economild
Contemporâned

\title{
A "NOVA ECONOMIA DO PROJETAMENTO" NO COMBATE À COVID-19 E AS CAPACIDADES ESTATAIS CHINESAS COMO FORÇA POLÍTICA ESTRATÉGICA
}

\author{
Elias Jabbour ${ }^{a}$ \\ Bernardo Salgado Rodrigues ${ }^{b}$
}

\begin{abstract}
aProfessor Adjunto da Faculdade de Ciências Econômicas e dos Programas de Pós-Graduação em Ciências Econômicas (PPGCE) e em Relações Internacionais (PPGRI) da Universidade do Estado do Rio de Janeiro (UERJ). Rio de Janeiro, RJ, Brasil. ORCID: https://orcid.org/0000-0003-0946-1519.

${ }^{\text {b}}$ Doutor em Economia Política Internacional pela Universidade Federal do Rio de Janeiro (UFRJ). Rio de Janeiro, RJ, Brasil. Pesquisador do Grupo de Trabalho "China y el Mapa del Poder Mundial" do Consejo Latinoamericano de Ciencias Sociales (CLACSO). Buenos Aires, BS AS, Argentina. ORCID: https://orcid. org/0000-0002-6439-8359.
\end{abstract}

Recebido em 29 maio 2020

Aceito em 06 abril 2021

RESUMO: O presente artigo busca demonstrar dois fenômenos interligados na China. O primeiro deles é o processo histórico que envolveu mudanças institucionais ocorridas ao longo dos últimos 40 anos e saltos qualitativos no seio do setor estatal na economia chinesa. Esses elementos foram fundamentais para o surgimento de novas e superiores formas de planificação econômica, que, por sua vez, fez emergir um estágio superior de desenvolvimento que denominamos de "Nova Economia do Projetamento" - sendo este novo desenvolvimento também síntese de uma série de capacidades estatais construídas ao longo do tempo. O segundo fenômeno tem relação com as citadas capacidades estatais criadas, aqui entendidas como o elo explicativo fundamental no combate ao coronavírus pari passu a uma flexibilidade adaptativa e uma eficiência célere na contenção interna, reforçando o potencial da China e de sua projeção como ator político internacional.

PALAVRAS-CHAVE: China; Covid-19; nova economia do projetamento; planejamento econômico; capacidades estatais.

CLASSIFICAÇÃO JEL: O1; O2; P2.

Correspondência para: Elias Jabbour

Contato: eliasjabbour@terra.com.br 


\title{
THE "NEW PROJECTMENT ECONOMY" IN THE FIGHT AGAINST COVID-19 AND THE CHINESE STATE CAPABILITIES AS A STRATEGIC POLITICAL FORCE
}

\begin{abstract}
This article seeks to show two interconnected phenomena in China. The first is a historical process that took place in the past 40 years involving institutional and qualitative changes in the state-controlled portion of the Chinese economy. Such changes have brought about new and superior forms of economic planning, based on which a higher stage of development pattern has emerged. We call this new development pattern "New Projectment Economy" and it synthesizes a series of state capacities built over time. The second phenomenon relates to how the state capacities created in the past decades have allowed the country to show adaptive flexibility and rapid efficiency in the containment of Covid-19 crisis internally and thus explain China's successful response in the fight against the coronavirus. Such phenomena, pari passu, show China's potential and projection as an international political actor.
\end{abstract}

KEYWORDS: China; Covid-19; new projectment economy; economic planning; state capabilities. 


\section{INTRODUÇÃO'}

Em dezembro de 2019, médicos em Wuhan se depararam com os primeiros pacientes do novo coronavírus (Sars-CoV-2), responsável pela enfermidade da Covid-19. Em 30 de janeiro de 2020, a Organização Mundial da Saúde (OMS) anunciou que o surto era uma emergência de saúde pública de interesse internacional. Em 11 de março de 2020, foi declarada a pandemia. Desde então, o governo chinês vem se esforçando para qualificar sua capacidade de prevenção, controle epidêmico e sistema de gestão da saúde pública emergencial do país. O surto vem se constituindo como um teste para a governança da China (HUI, 2020); teste este que também se dá por meio de uma intensa guerra de informações envolvendo o governo dos Estados Unidos e a própria China.

Esta contenda internacional entre os dois países pode desviar a atenção do que realmente importa em termos de desenvolvimento econômico em perspectiva comparada: como a China tem conseguido não somente resistir à pandemia, quanto empregar de forma rápida todos os meios necessários, e, em 72 dias, declarar a reabertura da cidade de Wuhan? Quais capacidades foram postas em funcionamento e como elas foram sendo construídas ao longo das últimas décadas? Quais os traços distintivos do caminho chinês em comparação a outras trajetórias recentes de desenvolvimento?

A China pode ser observada como um paradigma. Seu crescimento econômico, no período entre 1980 e 2018 foi excepcional, a média de crescimento do Produto Interno Bruto (PIB) real no período foi de 9,2\% a.a. Portanto, há mais de quatro décadas que o país cresce acima da média internacional, de forma quase que ininterrupta. A taxa média de crescimento do PIB per capita da China por mais de 35 anos, por sua vez, alcançou cerca de 9,0\% a.a., sendo que a renda per capita (por paridade de poder de compra) cresceu 36 vezes: passou de apenas US\$ 250 dólares em 1980, para US\$ 8.827 em 2018. Este processo foi acompanhado de uma elevada taxa de investimento com média de $36,9 \%$ do PIB em 1982/2011, e acima de $40 \%$ a partir de 2004 até a atualidade.

Não são poucos os ângulos pelos quais esse processo pode ser explicado. Por exemplo, na literatura internacional já existe um grande acúmulo de estudos com diferentes visões. Naughton $(1996,2007,2017)$, em sua grande obra contempla uma visão para quem o crescimento chinês seria expressão de um bem-sucedido capitalismo de Estado. Dentre as abordagens mais histórico/institucionais, destacamos

\footnotetext{
World Bank Data (2019).
} 
Nolan (2001), e entre os que apostam numa via em consonância com abordagens neoclássicas destacamos os trabalhos de Lardy $(2014,2018)$.

Por outro lado, podemos recolocar a hipótese que relaciona esse crescimento econômico contínuo como fruto de mudanças institucionais que tanto conformaram o papel do Estado e do setor privado ao longo do processo (JABBOUR; DANTAS, 2017; JABBOUR; PAULA, 2018) quanto criaram condições ao surgimento de uma nova classe de formações econômico-sociais, o socialismo de mercado. ${ }^{2}$ Alguns fatores podem ser elencados sobre a consolidação desta nova formação econômico-social (NFES).

A título de exemplo, podemos elencar cinco pontos: i) um poder político de novo tipo, fundado nos marcos da Revolução Nacional e Popular de 1949, capaz de comandar as mudanças institucionais necessárias ao enfrentamento das contradições inerentes ao processo de desenvolvimento; ii) um profundo e capilarizado sistema financeiro público de longo prazo; iii) a transformação do comércio exterior em um "bem público planificado e de Estado" (JABBOUR; DANTAS, 2017, p. 794); iv) a formação e o fortalecimento, desde a década de 1990, de 97 grandes conglomerados empresariais estatais (GCEE); e v) surgimento, em 2003, da State-Owned Assets Supervision and Administration Commission (SASAC), instituição responsável por gerir os ativos e interesses estatais nas GCEE.

Bom notar que o surgimento da citada NFES é fruto de sucessivas inovações institucionais que, também, acomodaram a coabitação - nesta mesma formação - de uma miríade de modos de produção, tendo como dominante o encabeçado pelo setor público (socialista). ${ }^{3}$ Percebe-se contínuo progresso técnico verificado nos GCEE desde a execução de políticas industriais mais proativas redundando no surgimento de novas e superiores formas de planificação econômica no país.

Podemos inferir que o círculo virtuoso existente entre a elevação técnica nas GCEE e o surgimento de formas superiores de planificação econômica levaram ao reaparecimento da outrora existente, e percebida por Ignácio Rangel, "Economia do Projetamento" - agora sob a insígnia da "Nova Economia do Projetamento" (NEDP). Esta NEDP também pode ser vista tanto como um estágio superior de

2 Sobre o socialismo de mercado como uma nova classe de formações econômico-sociais, ver Gabriele (2020), Jabbour (2019), Jabbour e Dantas (2018) e Gabriele e Schettino (2012).

3 Sobre a dinâmica entre diferentes modos de produção coabitando, em unidade de contrários, na NFES que surge na China, ler Jabbour e Dantas (2020). Em resumo, podemos dizer que na China de forma simultânea convivem modos de produção de diferentes épocas históricas, sendo o modo de produção socialista, o dominante que engloba tanto as GCEE, o sistema financeiro, quanto as grandes empresas coletivas. Outros modos de produção que operam naquela FES são o capitalismo e a pequena produção mercantil na agricultura. 
desenvolvimento do socialismo de mercado chinês quanto como uma síntese de uma série de capacidades estatais construídas ao longo do tempo e que têm sido fundamentais ao combate à Covid-19. ${ }^{4}$

O presente artigo busca correlacionar o surgimento desta NEDP e as capacidades estatais que a geraram como forma de encontrar uma síntese sobre as razões da eficiência chinesa no combate à Covid-19. Em outras palavras, buscar-se-á demonstrar que o Estado chinês é a força política que detém o controle dos fatores estratégicos e dos setores produtivos em indústrias-chave, concluindo-se que seus saltos qualitativos de planejamento estatal possibilitaram uma flexibilidade adaptativa e eficiência célere na contenção interna, reforçando a nossa interpretação que percebe nesta NFES uma avançada engenharia político-social, alçando a República Popular da China a ator político internacional de primeira linha.

Além desta introdução e das considerações finais, este trabalho será divido em outras duas seções. Inicialmente exporemos uma definição e o lastro teórico-histórico que sustentam a hipótese do surgimento na China de um estágio superior de seu socialismo de mercado, sob a insígnia da NEDP. Na segunda seção, são apresentadas algumas definições do conceito de capacidades estatais e seus fatores e fatos empíricos deste conceito na China que corroboram esta assertiva, fundamentados no contexto da pandemia da Covid-19 a partir de três fatores: contenção interna, cooperação internacional e recuperação econômica (WANMING, 2020).

\section{A NEDP: DEFINIÇÃO E NOTAS TEÓRICO-HISTÓRICAS}

\subsection{ECONOMIA CHINESA: UM OLHAR EM DINÂMICA}

É imperativo afirmar que, de nossa parte, o resgate do conceito de "Economia do Projetamento", lançado pelo economista brasileiro Ignacio Rangel em uma distante obra datada de 1959, é parte de um processo de busca por novos aportes teóricos e conceituais diante da mudança de face do sistema econômico chinês; mudança esta que ficou evidente ao grande público com o anúncio e os impactos do pacote fiscal de US\$ 586 bilhões lançado em 2008, tendo como protagonistas produtivos e financeiros as GCEE

\footnotetext{
4 A título de exemplo, e adiantando argumento, a formação das 97 GCEE, o aparelhamento de um imenso sistema de bancos públicos voltados a investimentos de longo prazo, e a crescente capacidade estatal de coordenar e lançar mão de políticas de socialização do investimento são capacidades estatais fundamentais e que dão conteúdo à NEDP. A noção de ciclos/ondas de inovações institucionais é fundamental como forma de dar caráter de processo histórico à formação da NEDP.
} 
e o sistema financeiro público de longo prazo. ${ }^{5}$ Em certa medida, o Estado - com seus braços produtivo e financeiro - ao protagonizar tal ordem de investimentos encampara, nas palavras de Henderson (1951, p. 234) o papel de "empreendedor-em-chefe", colocando o setor privado como ancilar a um processo em que as GCEE assumiram os pontos nevrálgicos e com alto grau de monopólio da economia nacional chinesa.

Esta transformação na estrutura produtiva e financeira chinesa remonta principalmente à segunda metade da década de 1990 com a corporatização das antigas empresas estatais, transformadas, inicialmente, em 197 GCEE com um novo atributo: a orientação ao mercado. ${ }^{6}$ Em paralelo, um conjunto de inovações institucionais abriu condições à transformação da economia chinesa em uma moderna economia monetária com a formação de, inicialmente, quatro bancos estatais de desenvolvimento. A conta de capitais fora fechada e a taxa de câmbio maxidesvalorizada em 1994 (BRESSER-PEREIRA; JABBOUR; PAULA, 2020). ${ }^{7}$

Um olhar de conjunto sobre a evolução dos marcos institucionais que foram dando contornos especiais à economia chinesa é sugestivo sobre as delimitações e o lugar do Estado - sob forma de suas instituições, empresas e sistema financeiro - e o setor privado. Segundo Jabbour e Paula (2018), a cada ciclo de inovação institucional ocorre uma permanente reorganização de atividades mediada pelo surgimento cíclico de instituições que delimitam a citada reorganização de atividades entre os setores estatal e privado da economia.

Os citados ciclos ocorridos desde 1978 não permitiram somente que o processo de desenvolvimento chinês incorresse em "soluções de continuidade" (MEDEIROS, 2013, p. 435), mas também levou a um crescimento quantitativo do setor privado na economia, enquanto que o Estado elevou seu papel de forma qualitativa via controle político do país (característica fundamental da NFES em relação às formações econômico-sociais

\footnotetext{
5 Pode-se dizer que houve uma verdadeira intervenção em massa do Estado na economia, o que fortalece a nossa menção à mudança de face do sistema econômico chinês. Em apenas alguns anos o país estaria cortado por novos e milhares quilômetros de linhas de trens de alta velocidade, metrôs e estradas. Cabe destacar que: i) A relação investimento/PIB chegou à impressionante marca de 47,6\% em 2011, configurando capacidade produtiva instalada pronta a responder não somente a desafios internos, mas também externos, como o proposto pela configuração de uma Nova Rota da Seda (terrestre e marítima), lançada pelo presidente chinês Xi Jinping em setembro de 2013 e ii) Dados do National Bureau of Statistics of China de 2016 (NBSC) mostram que a malha ferroviária chinesa saltou, entre 2009 e 2015, de 86 mil para 121 mil quilômetros de extensão.

6 Gabriele (2020) e Naughton (2007) analisam com riqueza de detalhes este processo de corporatização das empresas estatais chinesas.

7 Quando tratamos da formação de uma moderna economia monetária a intenção é dissertar sobre a formação de uma economia amplamente baseada no crédito de longo prazo sob a forma de cerca de 30 bancos de desenvolvimento de nível nacional, provincial e municipal.
} 
capitalistas) - pelo Partido Comunista da China (PCCh) - que se estende pela grande manufatura, sistema financeiro, política de juros, câmbio, fluxo externo de capitais e demais mecanismos de coordenação e socialização do investimento, sendo a principal delas a SASAC.

É sob o acicate destes ciclos de inovações institucionais que nos amparamos para tratar o edifício econômico e social chinês como uma formação econômico-social distinta, uma NFES. Esta NFES possui regularidades que a distinguem. ${ }^{8}$ Exemplo de uma regularidade distintiva (o crescimento do setor privado não ocorre em detrimento de uma diminuição do papel do Estado) está no fato de apesar de ser uma dinâmica onde o Estado detém somente 30\% do controle sobre os fluxos de renda do país (PIKETTY et al., 2017; NAUGHTON, 2017; NOGUEIRA; GUIMARÃES; BRAGA, 2019), de forma contraditória, atualmente o Estado chinês conta com uma capacidade muito maior de intervenção sobre a realidade econômica e social do que o tinha no final da década de 1970, sobretudo no exercício das prescrições de Minsky (1986) de ser intérprete do duplo papel de "big government" e "big bank". Esta capacidade maior de intervenção ficou evidente durante o enfrentamento à Covid-19.

Podemos dizer que a NEDP pode ser vista como uma antítese à financeirização; uma economia voltada, completamente, ao setor produtivo (acompanhada por forte repressão financeira), pela busca da fronteira tecnológica e, como demonstrado no combate à Covid-19, com capacidade de construção de grandes bens públicos. Uma engenharia social em estado permanente de New Deal rooseveltiano, baseada em amplas capacidades estatais, tendo como núcleo as GCEE. ${ }^{9}$ Sendo as GCEE o braço público responsável pela geração de efeitos de encadeamento a todo o conjunto da economia nacional chinesa, essa NEDP já nasce com um traço que a distingue das economias capitalistas no qual o fator principal de produção tem caráter privado: a NEDP carrega

8 Algumas dessas regularidades foram apresentadas por Jabbour e Dantas (2018, p. 79). São elas: i) a existência, nesta NFES, de distintos modos de produção que não se limitam a coexistir, coabitam em conflito e exercem pressão - uma sobre a outra - aberta entre si; ii) a lei do valor não é passiva de superação sob o "socialismo de mercado" visto como parte do início do processo histórico de construção do socialismo; iii) o surgimento cíclico de instituições que delimitam uma contínua reorganização de atividades entre os setores estatal e privado da economia; iv) existe uma regularidade neste processo cíclico de reorganização de atividades entre os dois setores, o crescimento do setor privado não ocorre em detrimento de uma diminuição do papel do Estado; e v) o planejamento é uma lógica de funcionamento fundamental do socialismo.

9 A diferença entre os Estados Unidos (EUA) comandado por Roosevelt e a China atual pode se restringir à estrutura dominante de propriedade entre os dois países e o sistema social que ambos advogam, o socialismo na China e o capitalismo nos EUA. Porém, essas diferenças não são suficientes para deslocar o que chamamos de "estado permanente de New Deal rooseveltiano. Nossa ideia aqui é ilustrar o processo chinês partindo de um paralelo histórico. 
em seu bojo a possibilidade de superação do que se convencionou chamar de incerteza keynesiana.

Esta possibilidade de superação da incerteza keynesiana reside principalmente no fato de a decisão de investimento capaz de colocar em funcionamento toda a economia não está em mãos privadas, e sim no Estado com suas empresas e bancos - ambos públicos. O setor privado na China, diferentemente do capitalismo - que se utiliza da primazia sobre o investimento para fins políticos -, é ancilar e dependente das encomendas geradas pelas decisões de investimentos estatais. Este elemento por si só já serve como parâmetro histórico de como a incerteza é tratada no socialismo sob a égide da NEDP. Esta característica da NEDP guarda imenso acúmulo empírico, a começar pela análise dos grandes pacotes fiscais executados desde o final da década de $1990{ }^{10}$

\subsection{VOLTANDO A IGNACIO RANGEL: A "ECONOMIA DO PROJETAMENTO"}

O que seria a "Economia do Projetamento" para Ignacio Rangel? De forma objetiva, trata-se de uma economia surgida nos marcos dos paradigmas e inovações institucionais i) da Revolução Russa; ii) do keynesianismo; e iii) da economia monetária (CASTRO, 2014 , p. 202). Rangel faz transparecer em toda sua obra que a relação entre os fatos históricos expostos evidencia a planificação econômica como o maior fato econômico do século XX. As evidências que chegam da China são fonte de material suficiente para estender essa percepção ao presente século.

As três ocorrências citadas mudaram substancialmente a face do sistema econômico desde então, tendo a planificação soviética como seu paradigma principal, seguida pelo papel do princípio da demanda efetiva na intervenção sobre o ciclo econômico no mundo capitalista. Assim, Keynes e a Gosplan soviética tornaram-se dupla face de uma mesma moeda. Segundo Rangel (2005, p. 291): “[o] homem, nos dois casos, intervindo conscientemente na história, procura obter pelo planejamento o que antes se fazia por si, pois a sociedade que não garantir essas condições entra em crise e perece”.

Poder-se-ia conceituar esta Economia do Projetamento como um novo modo de produção cujo objetivo é produzir valor de uso regulado pela vontade consciente e racional através do cálculo econômico. Esta economia:

${ }_{10}$ Sobre a possibilidade da superação da incerteza keynesiana na NEDP, ler Jabbour et al. (2020). 
[...] Plano e projeto ${ }^{11}$ através da seleção de técnicas e alocação de recursos, são seus instrumentos fundamentais. Isso difere do capitalismo onde a produção de valores de uso é regulada pelo mercado através do valor, seja ele explicado pelo trabalho, para os clássicos, ou pela utilidade marginal, para os neoclássicos. (CASTRO, 2014, p. 208)

Cada teoria emerge amparada em um conjunto de categorias e conceitos que dão conteúdo social e histórico à abstração. No caso do projetamento, Rangel deixa evidente o "custo" e o "benefício" como suas categorias fundamentais, o que implica que toda a teoria do projetamento não se trata somente de um esforço para buscar precisão entre ambos, mas - principalmente - a sua razão (RANGEL, 2005, p. 366-367). Outra definição anexa à teoria, que a nós é um paradigma de definição do que significa uma economia voltada à produção de valores de uso, está na riqueza como a qualidade que tem certas coisas úteis à sociedade humana (RANGEL, 2005, p. 367). A esta forma de conceituação de riqueza aplicamos ao caso chinês, tendo em vista os objetos de caráter socializante da governança chinesa e onde a planificação guarda imensa possibilidade à superação do que se convencionou chamar de fetiche da mercadoria.

Partindo somente dos princípios expostos até então, um atributo da "Economia do Projetamento" rangeliana pode se ampar nos marcos da maxirracionalização do processo de produção, o que coloca essa economia no extremo oposto da atual dinâmica de acumulação dominante, a financeirização. ${ }^{12}$

Essa maxirracionalização do processo de produção pode ser percebida como uma consequência do que Rangel (2005, p. 378) chamava de "convite à mudança", representados pelos efeitos globais e específicos de cada projeto ao conjunto da economia e da sociedade. ${ }^{13}$ De forma menos abstrata, podemos conceber que o projeto chega ao planejamento via saltos de um desequilíbrio a outro até o momento em que a tecnologia se transforma em instrumento fundamental à atração que a razão pode exercer sobre o processo produtivo. Mantém-se uma lógica fundamental do processo de desenvolvimento: com a técnica elevando a patamares superiores a divisão social do trabalho, mudando assim - a face do sistema.

11 A nós é claro que planejamento se relaciona também com variáveis “macro" enquanto o projetamento é "micro", algo com relação direta ao desenvolvimento das empresas e seus projetos.

12 Sobre a financeirização como padrão sistêmico de acumulação, ler Braga (1997).

13 Exemplo dos efeitos globais e específicos, ao caso chinês, são os imensos projetos de interconexão regional que têm sido executados no país desde o lançamento, em 1999, do "Grande Programa de Desenvolvimento do Grande Oeste”. Podemos dizer que a China é uma economia movida a grandes projetos. 
A teoria rangeliana se transforma em profundo veio de caráter humanista na forma como apreende o desemprego como uma circunstância inerente ao capitalismo. A nossa leitura da proposta de Rangel nos leva a crer que a Economia do Projetamento (que pode ser lida como "socialismo") é a superação desta circunstância (desemprego), levando à criação de uma "macroeconomia do projeto" voltada completamente a esta proposta de superação. Vejamos:

O projetista, ao decidir entre duas técnicas, deve sentir-se agente da sociedade, o que exige que nada aceite sem exame. Sua ação deve ser orientada por um plano-mestre geral [...] e esse plano será diferente segundo haja ou não desemprego. A ele deve subordinar-se toda a sua ação, como tático do desenvolvimento, que é. Se há desemprego, deve trabalhar para induzir o emprego pleno; alcançado este, deve buscar a gradual retirada do trabalho dentre os fatores de produção. (RANGEL, 2005, p. 405)

Essa noção é novamente alçada à tona pelo mestre maranhense, afirmando Rangel (2005, p. 433): “[n]esse caso, a estratégia geral do desenvolvimento deve ajustar-se a esta circunstância, e o projetista, como tático do desenvolvimento, deve ajustar seus critérios a essa circunstância". ${ }^{14}$

Para fins de plena utilização de mão de obra, na macroeconomia da Economia do Projetamento, a alocação de recursos - via plano - pode ocorrer sem elevação da técnica (CASTRO, 2014, p. 219). Isso não significa uma negação da destruição criativa, mas sim na sua planificação e incorporação, ou não, ao projeto. Em uma situação com este dispositivo ex ante a elevação da técnica deve andar ao lado, por parte do projetista, da necessidade de novos campos de acumulação capazes de admitir maior emprego de mão de obra. Em um rumo mais estratégico, a redução da jornada é a opção a ser lançada lastreada por um poder político que persiga um horizonte socializante.

\subsection{A NEDP NA CHINA CONTEMPORÂNEA (UM RESUMO)}

Dois fatos políticos e econômicos são fundamentais à compreensão do ressurgimento na China da "Economia do Projetamento" rangeliana. O primeiro está no fato de o colapso da União Soviética ter levado à regressão, no mundo, da forma original de

\footnotetext{
14 Vejamos outro potencial exemplo da prática deste tipo de assertiva rangeliana: apesar de a China estar crescendo a taxas menores nos últimos quatro anos, a média de geração de empregos urbanos continua a mesma: 13 milhões ao ano.
} 
"Economia do Projetamento" em prol da financeirização e do keynesianismo militarizado nos EUA. O Consenso de Washington inaugura uma "nova ordem dos mercados" ${ }^{15}$ Surge uma crise ambiental sem precedentes, com a própria China como núcleo. O progresso técnico observado desde o surgimento de novos paradigmas tecnológicos no Japão, em grande medida, não foi posto à produção de utilidades em prol do bemestar humano. Ao contrário, alimentou a lógica financeirizada. ${ }^{16}$

A segunda ocorrência tem relação direta com a China e seus imensos desafios sociais e ambientais acumulados ao longo das últimas duas décadas. Enfrentar tais desafios demandara ao Estado mudança de foco à produção de grandes bens públicos (valores de uso em massa). Este desafio ocorre no mesmo tempo histórico em que a complexidade da economia chinesa foi levando o país a uma maior descentralização de uma economia centralmente planificada que, curiosamente, já caminhava no sentido da maior autonomia das províncias e mesmo das empresas. O projeto como núcleo central da economia chinesa tem ganhado muita força sob a forma de grande oferta e demanda de engenheiros e economistas de projetos naquela realidade sob pressão tanto de questões sociais latentes quanto da tarefa histórica de alcançar a fronteira tecnológica na maior parte dos setores possíveis.

Logo, é implícito que a China é parte deste esforço internacional para alcançar a fronteira da tecnologia. E a NEDP tem essa distinção, pois sua existência é condicionada à absorção e à produção da técnica mais avançada existente no mundo. Esse esforço chinês que a tem colocado entre os partícipes desta corrida, que já se transformou em uma guerra comercial e tecnológica com um fim imprevisível, nasce na primeira década do presente século e tem razão na exaustão do crescimento realizado com tecnologia importada e consequente declínio da complementaridade tecnológica com os EUA e o Japão (MEDEIROS, 2017). ${ }^{17}$ Como já exposto acima, exaustões na dinâmica chinesa de desenvolvimento, até então, poderiam ser percebidas em um modelo que pouco

15 Sobre a "nova ordem dos mercados" e o retrocesso percebido ao nível da teoria econômica ler Fiori (1997) e Bresser-Pereira (2009). Belluzzo (1997) aponta para a falácia inerente às noções propagadas pelo Consenso de Washington e para a intensificação do papel do Estado no processo de "globalização".

16 Sobre a relação entre progresso técnico e retroalimentação da financeirização, ler Guttmann (2008).

17 Algumas informações complementares. Desde o $11^{\circ}$ Plano Quinquenal (2006-2010), a prioridade são investimentos em tecnologias centrais como semicondutores e softwares e, desde 2010, incluiu-se a corrida em torno do domínio das técnicas de Inteligência Artificial em que algumas GCEE em conjunto com a Huawei já projetam a plataforma 6G. Entre 2005 e 2010, os investimentos estatais em Ciência, Tecnologia e Inovação aumentaram em 170\% O relatório referente ao ano de 2018 da Organização Mundial de Propriedade Intelectual (OMPI) indica que dos cerca de 12 milhões de pedidos de registo de patente, 5,7 milhões foram originários da China. Sobre a evolução recente da China na indústria de semicondutores ler Majerowicz e Medeiros (2018) e Majerowicz (2019). 
privilegiou a distribuição de renda nos 20 primeiros anos das reformas e que foi assentando-se muito no investimento em detrimento do consumo. Bom afirmar, também, que a referida dinâmica de acumulação também atingiu um limite tendo vista o alto custo ambiental do processo. A NEDP na China pode ser vista como uma resposta a estes desafios.

As políticas industriais chinesas, neste século, passaram a ser mais proativas em matéria de produção de inovações endógenas com busca constante do estado da arte em matéria de desenvolvimento técnico. É esta natureza proativa que abre espaço ao plano e ao projeto como prováveis sucessor do mercado como o núcleo do funcionamento da economia; o surgimento e a corporatização das GCEE as colocaram na linha de frente do progresso técnico e na gestão de novas e superiores formas de planificação perceptíveis pela incorporação e o convite à mudança aludida por Rangel exercida pelo "progresso técnico". O caso da plataforma $5 \mathrm{G}$ e das ferrovias de alta velocidade é exemplar e em tal a China atingiu a fronteira tecnológica. ${ }^{18}$

O "esforço maior" no rumo da conformação de um estágio mais avançado do socialismo de mercado pode ser percebido no megaprojeto "Made in China 2025" lançado em 2015. ${ }^{19}$ De imediato afirmamos que, caso o plano obtenha êxito, a China provavelmente se colocará como a maior potência tecnológica do mundo no presente século, com todas suas consequências geopolíticas anexas. Destacamos, nas entrelinhas do projeto, a importância crucial dada aos dispositivos de Inteligência Artificial que se transformou em instrumento auxiliar à capacidade estatal de monitoramento dos casos de Covid-19 e seu devido encaminhamento.

Fica evidente a partir da evolução do processo de desenvolvimento recente da China de uma NEDP ressurgida como resposta aos desafios e contradições criadas pelo próprio processo de desenvolvimento, assim como das capacidades estatais como causa e consequência das novas e superiores formas de planificação econômica - que o país estava pronto ao maior desafio da história recente do país e do mundo. As aludidas capacidades

\footnotetext{
18 Os EUA não possuem uma única ferrovia de alta velocidade. Sobre o espetacular avanço das ferrovias de alta velocidade na China no pós-2008, ler Lo e Wu (2014).

19 Sobre o "Made in China 2025”, ver State Council (2015).
} 
estatais tornaram-se força estratégica ao combate da Covid-19 e ao demonstrarem isso, impõe ao analista a necessidade de novas abordagens teóricas e analíticas.

Veremos agora como as capacidades estatais, como expressão da NEDP estão sendo fundamentais à guerra contra a Covid-19.

\section{AS CAPACIDADES ESTATAIS CHINESAS NO COMBATE À COVID-19}

Visando atingir os objetivos pré-estabelecidos do presente artigo, cabe realizar uma sucinta explanação acerca do conceito de capacidades estatais. ${ }^{20}$ Como demonstrado esse conceito, e sua expressão concreta, ele pode ser visto como um dos pilares de sustentação da NEDP. Na literatura especializada, a variedade de definições no debate internacional, seja no âmbito da sociologia ou da economia política, converge para a retomada da centralidade do Estado na promoção do desenvolvimento econômico. Para Skocpol (1985, p. 9), seria a capacidade de implementar objetivos oficiais, especialmente sobre a oposição real ou potencial de grupos sociais poderosos, ou diante de circunstâncias socioeconômicas recalcitrantes. Numa linha auxiliar, Bichir (2016, p. 26) complementa que as capacidades do Estado são derivadas não somente das suas competências políticas, mas concomitantemente da construção de apoio à agenda entre os atores sociais, políticos e econômicos proeminentes, enquanto Jaguaribe (2016, p. 26) define como a "capacidade de formular políticas, construir e coordenar consensos, e abrir espaços de política pública (policy spaces) entre objetivos e oportunidades”.

A partir desse conjunto de definições que pautam a centralização do Estado no direcionamento estratégico, pode-se incorrer que a especificidade da capacidade estatal chinesa é a competência em formular, implementar, coordenar e proporcionar resultados previamente estabelecidos num projeto estratégico, através de um pacto social amplamente fundamentado e sustentado, delineados a partir de uma NFES estritamente relacionada cujo elemento interno mais avançado identificamos e nomeamos como a NEDP.

Após essa breve definição conceitual, reitera-se que as capacidades estatais chinesas, construídas ao longo das últimas décadas, tiveram sua eficiência testada a partir da pandemia mundial da Covid-19, doença causada pelo coronavírus SARS-CoV-2, que apresenta um quadro clínico que varia de infecções assintomáticas a quadros respiratórios graves. Desta maneira, serão analisadas três variáveis dependentes ocasionadas pelo ${ }^{20}$ Para maiores informações acerca das definições, dimensões e mensurações da capacidade estatal, reco-
menda-se o artigo de Aguiar e Lima (2019). 
surto do coronavírus, tal como proposto por Wanming (2020): o controle interno da doença, a cooperação internacional e a retomada do crescimento econômico. Desta forma, a partir da utilização do método empírico-dedutivo, esta pesquisa é justificada pela verificação da medição das capacidades estatais chinesas no combate à Covid-19, que se apresentam como uma prerrogativa que ratifica a hipótese central que relaciona o surgimento de novas e superiores formas de planificação econômica como a essência da NEDP.

\subsection{CONTENÇÃO INTERNA}

A contenção interna da epidemia demostra a particularidade das capacidades estatais chinesas para gerir uma situação de emergência em um país com mais de 1,4 bilhão de pessoas. O governo central chinês realizou o lockdown da cidade de Wuhan, epicentro da epidemia com mais de 11 milhões de habitantes, com um controle de circulação de pessoas completo e altamente restritivo, cancelando as festividades do Ano Novo chinês, fechando locais turísticos e obstando o transporte público. A partir de então, cada cidade e/ou província foi organizando os níveis de paralisação, a depender dos casos e dos riscos da região.

O marco temporal de análise dos dados apresentados corresponde ao quadrimestre posterior ao início da contabilização oficial, logo após o primeiro óbito na China, ocorrido em 11 de janeiro de 2020. Neste interregno, a China demonstrou uma elevadíssima capacidade de contenção do vírus, ratificado pelos dados oficiais apresentados. O número de casos confirmados no país era de 84.450 pessoas contaminadas, enquanto o número de óbitos era de 4.643 indivíduos, com uma taxa de letalidade de aproximadamente 5,5\%. O coeficiente de incidência por 100 mil habitantes, definido como o número de casos novos de uma doença, dividido pela população em risco da doença num espaço geográfico durante um tempo especificado, é de aproximadamente 5,8. 


\section{Gráfico 1 - Número de casos confirmados e número de óbitos na China (11 de janeiro a 11 de maio de 2020)}

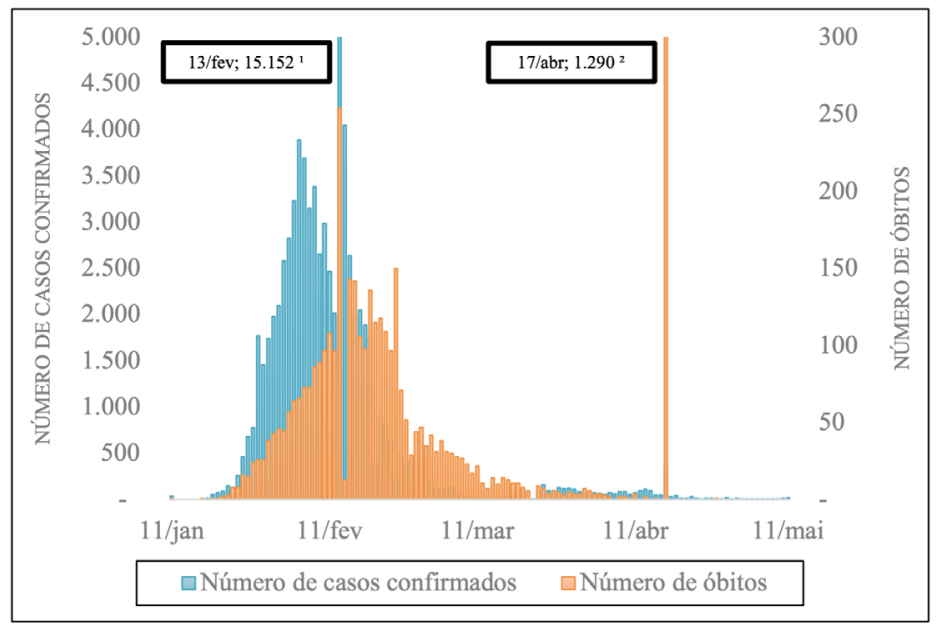

Notas: (1) O expressivo crescimento no número de casos registrados em 13 de fevereiro de 2020 deve-se à mudança na metodologia, passando a ser aceitos relatórios clínicos dos sintomas para enquadrar o paciente como caso suspeito. (2) No dia 17 de abril de 2020, a China anunciou uma revisão no total de vítimas pela doença, acrescentando 1.290 óbitos dos últimos meses que não haviam sido contabilizados, demonstrado na elevação abrupta no gráfico.

Fonte: Elaboração própria com base em dados de World Health Organization (WHO, 2020c).

Em termos comparativos a nível global, considerando-se o mesmo horizonte de tempo nos países do G-20, a China também evidenciou uma superioridade inquestionável. Analisando-se o número de casos confirmados, enquanto na China havia 84.450 pessoas contaminadas, menos de $2 \%$ dos casos globais, os cincos países mais infectados do G-20 eram os Estados Unidos (com 1.300.000 infectados, com aproximadamente um terço dos casos globais), a Rússia (221.300), o Reino Unido (219.200), a Itália (219.100) e a Alemanha (169.600), em que o nível de infecção nos EUA era quinze vezes mais elevado do que na China; na Rússia, no Reino Unido e na Itália, o triplo; e na Alemanha, o dobro. Visualizando-se a taxa de incidência, enquanto a China exibia um coeficiente de aproximadamente 5,8, nos Estados Unidos eram de 448,9 por 100 mil habitantes; na Rússia, 193,1; no Reino Unido, 353,8; na Itália, 370,3; e na Alemanha 209,7.

Se analisados os dados referentes aos óbitos, os índices são ainda mais discrepantes. $\mathrm{Na}$ China, o número de mortos no período analisado correspondeu a 4.643 pessoas, enquanto os cinco países com maior letalidade do G-20, em termos absolutos, eram os Estados Unidos (76.900, dezessete vezes mais elevado que a China), Reino Unido (31.900, sete vezes mais elevado), Itália (30.600, sete vezes mais elevado), França (26.300, seis vezes mais elevado) e Brasil (10.600, duas vezes mais elevado). Em outros termos, enquanto o índice de letalidade na China estava em torno de 5,5\%, nos Estados 
Unidos era de aproximadamente 6\%; no Reino Unido, 14\%; na Itália, 14\%; na França, $15 \%$; e no Brasil, $7 \% .^{21}$

\section{Gráfico 2 - Número de casos confirmados e número de óbitos nos países do G-20 (11 de janeiro a 11 de maio de 2020)}

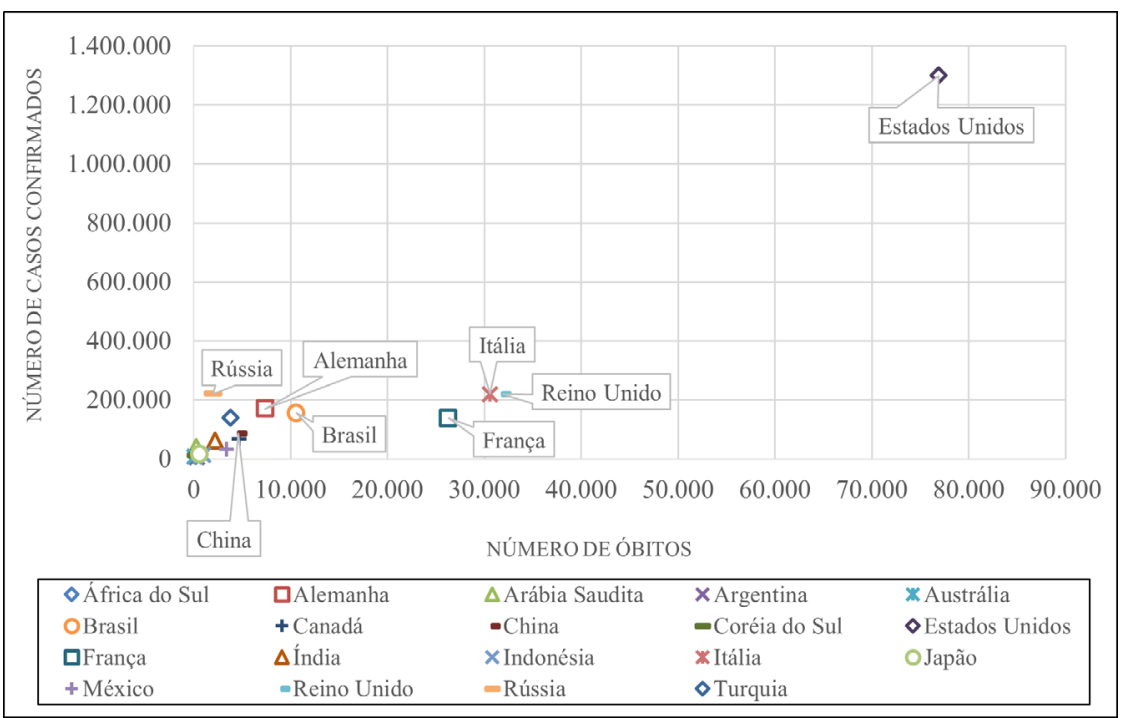

Fonte: Elaboração própria com base em dados de World Health Organization (WHO, 2020c).

Esse conjunto de dados ratifica a potencialidade das capacidades estatais chinesas a partir da perspectiva da NEDP. Em termos práticos, o controle epidêmico tem sido realizado a partir de diversos mecanismos. Dentre os principais, podem-se citar:

i) Foco no controle da pandemia e na ampliação do sistema de saúde, implementando-se uma estratégia abrangente de comunicação de riscos para informar regularmente a população sobre a evolução do surto, assim como o aprimoramento das medidas de prevenção, proteção e contenção.

ii) Imediata montagem de um mecanismo nacional de prevenção e controle, elevando o volume de materiais médico-hospitalares em todo o território nacional e mobilizando dezenas de milhares de profissionais da saúde, tais como as equipes médicas de 16 províncias que realizaram parceria com cidades de Hubei (HUI, 2020).

${ }^{21}$ Cabe salientar ainda que, dentre esses países, a China era o único a ter apresentado a curva de pico completa da doença e ter completado quatro meses desde o primeiro óbito. Em outros termos, a tendência do índice nos demais países é de aumento. 
iii) Construção de hospitais de emergência e hospitais especiais para doenças infecciosas agudas, que foram rapidamente instalados a fim de poder atender às necessidades de tratamento dos pacientes, tais como o Centro Médico Regional Dabieshan em Huanggang, o Hospital Huoshenshan e o Hospital Leishenshan, ambos em Wuhan - os dois últimos edificados em apenas dez dias, com velocidade 100 vezes superior à da construção normal de um hospital deste tipo.

iv) Utilização intensiva de tecnologia no desempenho ao combate à epidemia, um sistema de tracking individual que possibilitou um enfrentamento pontual sobretudo em medidas profiláticas e ligadas à restrição de circulação de pessoas, com o uso de aplicativos e rastreamentos de $Q R$ code que permitiam ou não a saída das pessoas de suas residências.

v) Realização de alerta em tempo real expedido a todos aqueles que podem ter tido contato com uma pessoa infectada durante o período de incubação do vírus, através da postagem de mensagens via contas oficiais no WeChat, que procuram pessoas que estiveram nos mesmos vôos, vagões de trem e ônibus com os pacientes que tiveram a infecção confirmada (HUI, 2020).

vi) Organização de pesquisadores de todo o país para levar adiante a pesquisa e desenvolvimento de medicamentos e vacinas, assim como a rapidez com que cientistas da China postaram a sequência genética e a condução de investigações para compreender a epidemiologia e a evolução desse surto.

Se o governo chinês, por meio de suas capacidades estatais, não tivesse tomado medidas de isolamento decisivas e efetivas, tanto a nível provincial quanto nacional, a epidemia do novo coronavírus poderia ter se expandido a outros países mais rapidamente, causando um impacto ainda mais intenso na segurança da saúde, na economia e na sociedade. Inclusive, este fato fez com que a Organização Mundial da Saúde (OMS) afirmasse que, "diante de um vírus até então desconhecido, a China empreendeu talvez o mais ambicioso, rápido e agressivo esforço de contenção de uma doença visto na história"22 (WORLD HEALTH ORGANIZATION, 2020b, tradução nossa).

Em suma, no que se refere à contenção no interior das fronteiras chinesas, as capacidades estatais da China apresentaram uma eficácia de mobilização sanitária e produtiva comparativamente inigualável no Ocidente. Em outros termos, como afirmou Cariello (2020, p. 16), "a resposta do governo demostrou a eficiência do Estado chinês em debelar uma aceleração do contágio na esfera doméstica, da mesma forma que, posteriormente, reforçou sua capacidade de projeção como um ator político de envergadura global”.

${ }^{22}$ No original, "in the face of a previously unknown virus, China has rolled out perhaps the most ambitious, agile and aggressive disease containment effort in history". 


\subsection{A COOPERAÇÃO INTERNACIONAL}

Este fato leva a segunda frente de atuação, relacionada ao desenvolvimento da cooperação internacional. Enquanto o epicentro da pandemia se movia do país asiático para a Europa, Estados Unidos e demais localidades, a China passou a investir no fortalecimento do seu papel de liderança em um movimento coordenado de colaboração a nível mundial. A partir da transparência e eficiência no compartilhamento de informações com a comunidade internacional e ampliação da atuação na OMS, a cooperação chinesa vem evidenciando a potencialidade das suas capacidades estatais na condução da crise, demonstrando o compromisso do PCCh em colaborar no plano multilateral com esforços de resposta global à pandemia.

A China afirmou que concederá apoio para as nações com sistemas de saúde mais frágeis e outras nações afetadas pelo novo coronavírus (CARIELLO, 2020), inclusive tendo realizado doações de cerca de 30 milhões de dólares à OMS, além dos 20 milhões de dólares previamente doados à organização desde o início da pandemia (CHINA, 2020a). De acordo com comunicados recentes do Ministério das Relações Exteriores da China, o país havia socorrido dezenas de países através do envio de doações, incluindo remessas de equipamentos de proteção individual (EPIs), testes para diagnóstico, know-how tecnológico em saúde e pessoal qualificado da área médica (CHINA, 2020b).

O país asiático vem oferecendo especialistas médicos e materiais médicos, tendo auxiliado mais de 130 países e quatro organizações internacionais, enviado 13 equipes médicas para 11 países e realizado mais de 70 videoconferências, compartilhando experiências e dados com mais de 150 países e regiões e organizações internacionais (CHINA..., 2020a), além de ter dividido com todos os protocolos de diagnóstico, tratamento e o programa de contenção da Covid-19 (WANMING, 2020). Complementarmente, o Exército de Libertação do Povo Chinês (PLA) compartilhou sua experiência no combate ao Covid-19 com militares da Tailândia, Indonésia, Malásia, África do Sul e Ucrânia por videoconferência em maio, com o objetivo de trocas de comando de emergência, prevenção e controle de epidemias, tratamento clínico e testes de diagnóstico (PLA..., 2020).

Concomitantemente, a China vem intensificando a cooperação internacional em matéria de pesquisa e desenvolvimento de medicamentos, vacinas e kits teste, com a promoção de ações coordenadas de alcance regional e global, visando, em última instância, o desenvolvimento de vacinas contra a Covid-19. Além de compartilhar a sequência completa do genoma do novo coronavírus, o país vem adotando abordagens tecnológicas abertas para a cooperação internacional, trabalhando com homólogos internacionais como Inovio, dos Estados Unidos, BioNTech, da Alemanha, e GlaxoSmithKline, da GrãBretanha (CHINA..., 2020b). Segundo o representante da OMS, Dr. Gauden Galea, os resultados desses estudos serão cruciais para ajudar a prevenir surtos semelhantes no 
futuro, ratificando a capacidade clínica, epidemiológica e laboratorial da China para conduzi-los (WHO, 2020a).

Este nível de cooperação internacional na área da saúde se manifesta em múltiplas dimensões centralizadas, principalmente, pelo aumento da demanda global por EPIs: “90 por cento dos antibióticos são fabricados na China, que também fornece 80 por cento das matérias-primas para todos os medicamentos do mundo"23 (MERINO, 2020). De $1^{\circ}$ de março a 4 de abril, a China exportou suprimentos médicos, incluindo 3,86 bilhões de máscaras, 37,52 milhões de roupas de proteção, 2,41 milhões de termômetros, 16.000 ventiladores, 2,84 milhões de kits de teste e 8,41 milhões de pares de óculos de proteção, no valor total de US\$ 1,4 bilhão (CHINA..., 2020a). Abrindo parêntese, evidente que a capacidade de resposta produtiva a uma imensa demanda global deve ser observada sob o ângulo da formação da NEDP na China.

Neste sentido, a cooperação internacional chinesa pode refletir no papel de sua liderança no campo da saúde pública global (WEN, 2020), preenchendo o vácuo de poder global deixado por Washington, principalmente após a suspensão temporária dos pagamentos dos EUA à OMS, em abril, por 60 dias. Este processo foi intensificado numa carta de Donald Trump direcionada ao diretor-geral da instituição, Tedros Adhanom Ghebreyesus, em 18 de maio de 2020, em que o presidente estadunidense ameaçou suspender permanentemente o financiamento dos EUA para a OMS e reconsiderar a sua participação no organismo das Nações Unidas. Para Trump (2020, tradução nossa), ao abordar a atuação da OMS, "está claro que os equívocos cometidos por vocês e sua organização na resposta à pandemia tiveram um custo enorme para o mundo" 24 além de abordar uma possível leniência por parte da OMS com a China, ao afirmar que "o único jeito de a Organização Mundial da Saúde continuar é se conseguir demonstrar uma real independência em relação à China”. ${ }^{25}$

O governo chinês reagiu imediatamente, afirmando que os Estados Unidos estavam usando a China como pretexto para se esquivar de obrigações financeiras que foram determinadas conjuntamente pelos Estados membros da OMS. Adicionalmente, em discurso na 73a sessão da Assembleia Mundial da Saúde, Xi Jinping (2020) garantiu que a China fornecerá US\$ 2 bilhões em dois anos no auxílio ao combate do Covid-19 e no desenvolvimento econômico e social nos países afetados, especialmente nos países em

${ }^{23}$ No original: "el 90 por ciento de los antibióticos se hacen en China, que además provee el 80 por ciento de materias primas para todos los medicamentos del mundo".

${ }^{24}$ No original, "it is clear the repeated missteps by you and your organization in responding to the pandemic have been extremely costly for the world".

${ }_{25}$ No original, "the only way forward for the World Health Organization is if it can actually demonstrate independence from China". 
desenvolvimento. Este valor representa quase a totalidade do orçamento anual da OMS, compensando o congelamento de repasses anunciado pelos Estados Unidos. Nesta mesma sessão, o presidente anunciou que a implantação de vacinas contra a Covid-19, que porventura forem desenvolvidas na China, tornar-se-ão um bem público global, assim que estiverem disponíveis. Tal fato visa demonstrar que esta nova formação econômicosocial visualiza não somente o lucro como prioridade imediata, mas o serviço à comunidade global diante da crise de saúde pública.

Abrindo parêntese, não se trata de generosidade pura e simples, na medida em que todo e qualquer Estado Nacional define estratégias à serviço de seus interesses. Mas aos chineses - com uma economia cada vez mais baseada na exportação de grandes bens públicos, em direção oposta à financeirização capitalista - é fundamental que a comunidade internacional seja composta por países cada vez mais soberanos e mais bem posicionados do ponto de vista material. Resumindo: não interessa aos chineses a pauperização da periferia mundial.

Retornando, desta forma, tanto o imbróglio sino-americano quanto a crise da Covid-19 são visualizados como uma oportunidade para seguir na direção em curso com a Nova Economia do Projetamento. Assim, reafirma a centralização interna de reforçar estruturas estatais, aumenta a legitimidade desse movimento endógeno, estabelece a capacidade chinesa de prover bens públicos globais e avança nas questões externas de governança global, política externa mais assertiva e protagonismo internacional, sendo, inclusive, reconhecida pela OMS como nova referência para a gestão global da saúde pública (WANMING, 2020). Em suma, o modus operandi mais enfático do governo chinês, na denominada "diplomacia das máscaras", tem sido fundamental para a construção de uma imagem positiva da China no exterior, uma concepção do "soft power chinês da saúde".

\subsection{RECUPERAÇÃO ECONÔMICA}

A terceira e última frente tem implicações na retomada do crescimento socioeconômico. Com o objetivo de minimizar os impactos econômicos da epidemia, o governo chinês lançou uma série de iniciativas, entre elas a retomada da produção e do trabalho de acordo com o grau de risco, o apoio das políticas fiscal e monetária às pequenas e médias empresas e regiões-chave, a estabilização efetiva do emprego, o controle da inflação, a proteção do bem-estar da população e o bom funcionamento das cadeias de produção e de suprimento para o comércio exterior (WANMING, 2020). É nesta frente que se destaca o já citado atributo da NEDP em relação às economias capitalistas na superação da incerteza keynesiana. 
No âmbito da crise econômica internacional, em relatório do denominado "The Great Lockdown", o Fundo Monetário Internacional (IMF, 2020) afirmou que a economia global deverá contrair-se mais do que durante a crise financeira de 2008-09. Como contrapartida desse cenário altamente negativo, observa-se que a rápida e sólida recuperação econômica chinesa já vem pontuando os estudos oficiais das instituições internacionais, revisando o impacto da crise em território chinês em termos altamente positivos, principalmente se comparado ao restante do mundo.

Gráfico 3 - Crescimento do PIB (variação percentual anual)

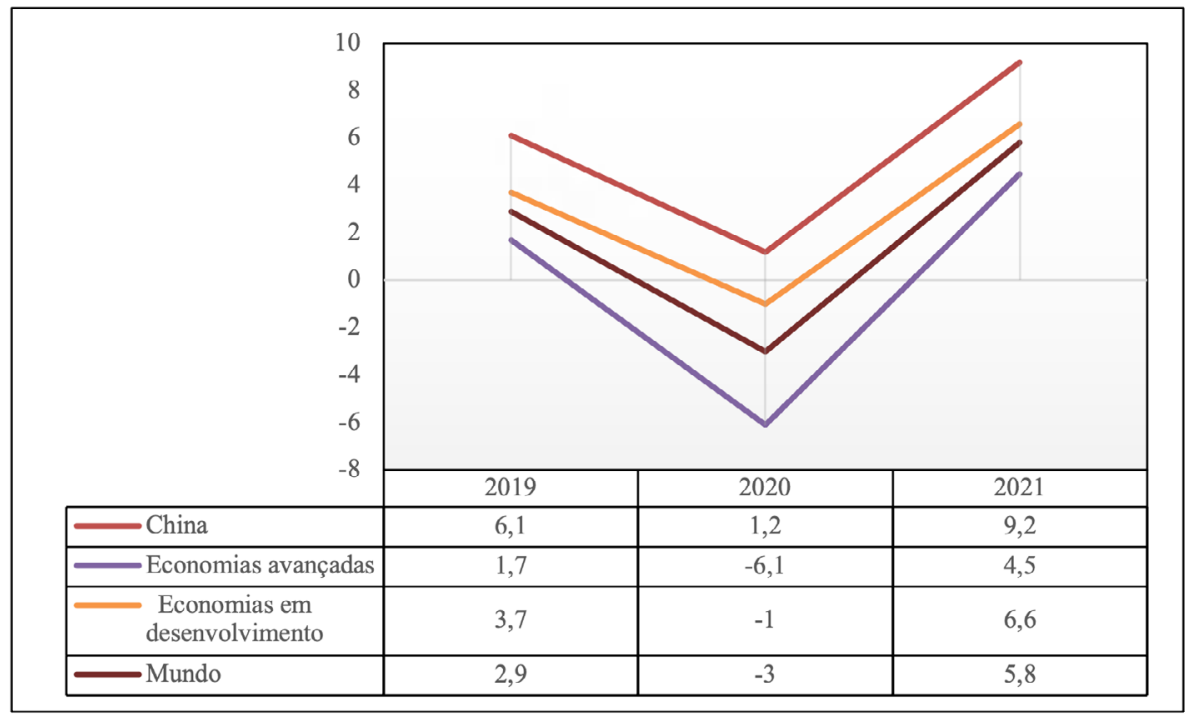

Fonte: Elaboração própria com base em dados de IMF (2020).

No comércio exterior, a Administração Geral das Alfândegas informou que, em abril, as exportações do país somaram 1,41 trilhão de yuans (US\$ 198,8 bilhões), ante uma queda de $11,4 \%$ no primeiro trimestre. As exportações chinesas de bens subiram $8,2 \%$ em termos anuais em abril, adicionando sinais de que o comércio exterior do país vem se estabilizando na medida em que as capacidades estatais, via projetamento, se sobressaem. As importações caíram 10,2\%, para 1,09 trilhão de yuans em abril, resultando em um superávit comercial de 318,15 bilhões de yuans. Nos primeiros quatro meses, o comércio exterior de bens totalizou 9,07 trilhões de yuans, uma queda de $4,9 \%$ em termos anuais. 
Gráfico 4 - Balança comercial pré e pós-Covid na China (em USD milhões)'1

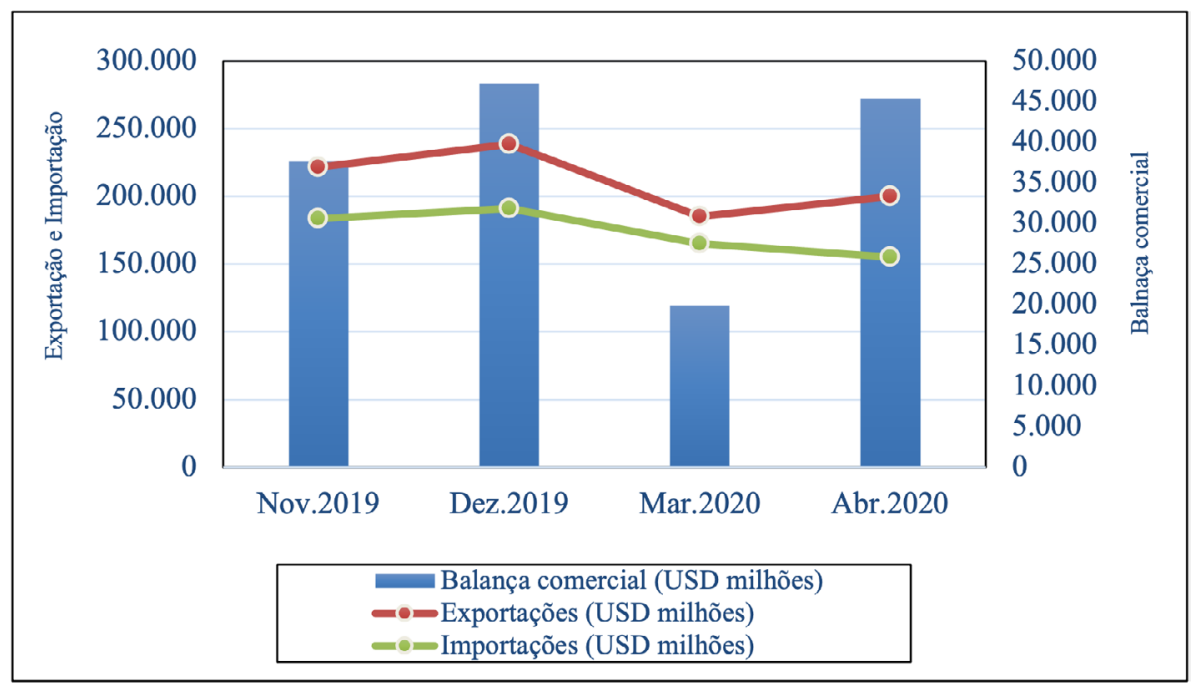

Notas: (1) Os dados referentes aos meses de janeiro e fevereiro não se encontravam disponíveis no site oficial do governo chinês. Fonte: Elaboração própria com base em dados do National Bureau of Statistics of China (NBSC, 2020).

No âmbito interno, as autoridades chinesas estão trabalhando para mitigar o impacto negativo dos choques na oferta e na demanda sobre a economia, com ações para contenção da crise, com estímulos realizados por meio de crédito e investimento. Dentre as medidas fiscais, cita-se a isenção para companhias aéreas de pagamento de tributos, a antecipação das quotas de emissão de dívidas de governos locais, a suspensão por três a cinco meses de contribuição à seguridade social, o subsídio para compra de automóveis, a redução dos preços de energia elétrica e dos impostos que incidem sobre pequenas empresas e para setores específicos (transporte, logística, aéreo, portuário), a postergação por três meses de aluguéis para empresas pequenas. No que tange às medidas monetárias, estabeleceu-se a redução do compulsório bancário e da taxa de juros de referência, a injeção de liquidez através de diversas linhas (aproximadamente RMB 1,7 trilhão), a liberação de empréstimos bancários para empresas (RMB 800 bilhões), e corte na taxa de recompra reversa (D’ATRI, 2020).

O controle parcial e total sobre a produção é um ponto positivo em momentos de crise, que possibilita uma regulação da economia através de um sistema híbrido entre capitalismo e economia planejada. A NEDP engendra como atributos a alta capacidade de planejamento e a execução dos projetos, coordenação de agentes e execução econômica. Tais atributos vêm sendo essenciais à resposta econômica célere da China pós-pandemia. Observa-se que a produção industrial, as vendas no varejo e os investimentos em ativos fixos, apesar do inevitável impacto negativo da pandemia, já demonstram sinais de 
retomada, ancorados inclusive pela elevação do estoque de crédito. Adicionalmente, a taxa de desemprego se manteve praticamente constante no período, com 3,62\% em dezembro de 2019 e 3,66\% em março de 2020.

\section{Gráfico 5 - Indicadores de atividade econômica na China (variação interanual)1}

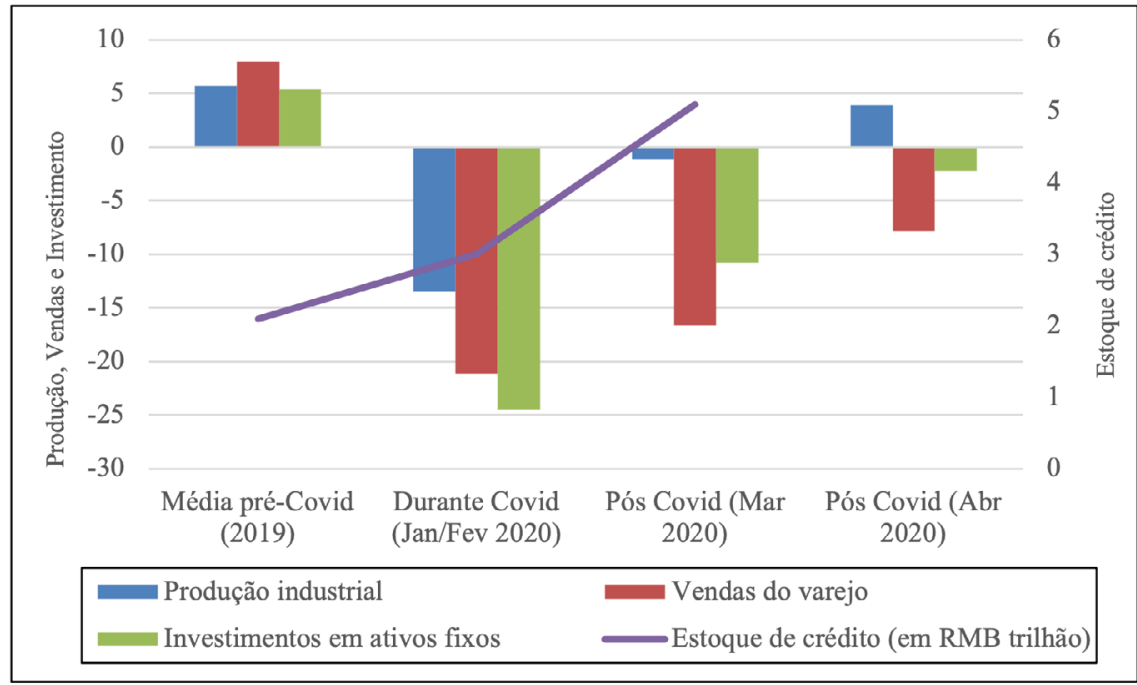

Nota: (1) Os dados referentes ao estoque de créditos do mês de abril ainda não se encontravam disponíveis na base de dados utilizada.

Fonte: Elaboração própria com base em dados de CEIC (2020).

A tendência é que a epidemia não altere as perspectivas de desenvolvimento da China no longo prazo, haja vista a histórica resiliência econômica chinesa, fruto da capacidade de mudanças institucionais cíclicas já expostas no espaço deste artigo e da superação da "incerteza keynesiana”. Tal qual fora realizado durante a crise de 2008, quando o Conselho de Estado da China anunciou um pacote de estímulos à economia na ordem de US\$ 600 bilhões, as capacidades estatais chinesas demonstraram uma elevada competência de coordenação - entre outras capacidades estatais -, como a entre o sistema financeiro público e a capacitação de execução por partes dos grandes conglomerados empresariais/estatais. Entretanto, a pandemia pode engendrar uma tendência de redução de metas quantitativas de crescimento, atrelando-se a metas mais qualitativas de PIB, conforme estabelecido em decisão inédita na terceira sessão do $13^{\circ}$ Congresso Nacional do Povo, em 22 de maio de 2020, cujo relatório de trabalho do governo entregue ao Congresso Nacional do Povo não continha uma meta de crescimento do PIB (KEQIANG, 2020). Caso essa disposição se concretize no médio e longo prazo, é mais um fator de ratificação de uma NFES. 
Em geral, a retomada mais enfática do crescimento no pós-pandemia possivelmente será realizada através de investimentos em infraestrutura, no âmbito da Nova Rota da Seda terrestre e marítima; pelo desenvolvimento das potencialidades da $4^{\text {a }}$ Revolução Industrial, em áreas como inteligência artificial, internet das coisas, tecnologias verdes e 5G; e redirecionamento para o mercado interno visando a redução da pobreza, num grande projeto que a pandemia pode inclusive vir a ser o elemento intensificador do processo, a partir da NFES e das capacidades estatais.

De acordo com Li (2020), a elevada capacidade do estado chinês demonstra uma responsabilidade econômica maior do que o mercado, haja vista o papel central desempenhado pelo PCCh na retomada econômica. Em outros termos, a NEDP e suas capacidades estatais chinesas coadunam a concretização de uma embrionária NFES, ratificada - no que tange ao combate à Covid-19, pela contenção interna, pela cooperação internacional e pela recuperação econômica.

Portanto, é provável que a China não altere o curso do seu projeto expansivo programado para a metade do século XXI; pelo contrário, deve acelerar a chamada two centenary goals (两个一百年), cujo objetivo de retomar sua grande civilização visa cumprir duas metas: i) acabar com a pobreza absoluta até 2021 (ano do centenário do Partido Comunista); e ii) ser um grande centro irradiador de poder no sistema internacional em 2049 (ano de centenário da fundação da República Popular da China). Desta forma, a meta de longo prazo mantida visa concluir a construção de uma sociedade moderadamente próspera e transformá-la num país socialista moderno, forte, democrático, culturalmente avançado e harmonioso (XI..., 2019).

\section{CONCLUSÕES}

O presente artigo buscou analisar como a conformação da NEDP, surgida no seio do modo de produção dominante à NFES, síntese de capacidades estatais criadas ao longo das reformas econômicas, foi elemento nuclear à rápida resposta chinesa ao desafio imposto pelo surgimento da Covid-19. Esta NEDP é produto de um processo histórico caracterizado pelo lançamento cíclico de inovações institucionais, que resultaram em aumento quantitativo do setor privado e saltos qualitativos do papel do Estado, gerando nova engenharia social distinta dos modelos apresentados no Ocidente.

O socialismo de mercado chinês pode ser visto como uma engenharia social de novo tipo, que tem na NEDP seu estágio superior. Anotações de ordem teóricas/históricas foram apresentadas com ênfase na teoria criada por Ignacio Rangel, em 1959, a qual lançamos mão como forma de compreender a mudança recente de face do sistema econômico chinês. A nós essa mudança de face, demonstrada no texto, deve ser 
acompanhada por novas abordagens em nível de teoria econômica. A NEDP é nossa proposta de compreensão ao novo estágio de desenvolvimento da economia chinesa.

Após um necessário preâmbulo de apresentação da NEDP partimos para a demonstração de seus atributos testados em meio à pandemia. Demonstramos que as capacidades estatais chinesas - compreendidas como o grau de eficiência e eficácia do Estado em administrar, gerenciar e superar desafios econômicos, políticos, sociais ou sanitários diante das condições materiais existentes, assim como projetar, coordenar e proporcionar resultados previamente constituídos num projeto estratégico - vem sendo o denominador comum das três frentes de atuação no combate à Covid-19: a contenção interna, a cooperação internacional e a recuperação econômica. Observa-se que as vantagens observadas em comparação aos outros Estados incidem em termos institucionais, no elevado grau de governança e na mobilização das diversas esferas da estrutura organizacional, sendo um fator que vem garantindo a eficiência da ação do governo contra a disseminação da Covid-19. Logo, pleiteia-se que o Estado não é o monopolizador do processo, e sim seu coordenador, que trabalha em conjunto com o setor privado no estabelecimento de metas e objetivos, através de uma "flexibilidade adaptativa diante das recorrentes transformações da conjuntura global - como num constante esforço de 'gestão planejada do imprevisível'” (RIBEIRO; PARANÁ, 2019).

Referente ao estudo de caso analisado, reitera-se que a pandemia da Covid-19 é um catalisador, um acelerador das transformações e tendências pré-existentes no sistema internacional. Ainda assim, toda e qualquer avaliação das consequências econômicas e políticas levarão anos para serem efetivadas em estudos acadêmicos. No mundo póspandemia, haverá uma nova ordem mundial? Quais as possíveis consequências para as relações econômicas entre as grandes potências no sistema internacional? Qual o futuro da hegemonia estadunidense e quais implicações na política internacional a pandemia causará no Ocidente? Há a possibilidade de o modelo chinês despontar como exemplo para o sistema internacional, um paradigma hegemônico no mundo pós-pandemia?

A partir desses questionamentos e da conclusão de que a China sai fortalecida no cenário geopolítico e geoeconômico, ratifica-se que a centralidade, a legitimidade, o planejamento e a capacidade de construir uma economia movida pela execução de grandes projetos podem influenciar significativamente nessa discussão, principalmente referente aos objetivos estratégicos em relação às quatro grandes transições que estruturarão o sistema internacional no século XXI: climática, energética, demográfica e tecnológica. E, uma vez que a financeirização desregulamentada não adentrou o Império do Meio como em outros países do mundo, o país asiático vem estabelecendo um objetivo societal e disponibilizando as capacidades estatais para atingi-lo. Em outros termos, uma fatia amplamente majoritária do Estado chinês vem sendo participante ativo nos módulos de acumulação de capital, radicalmente distinto ao modelo neoliberal, 
e que vem possibilitando aos chineses um controle fenomenal da pandemia em seu território através de capacidades estatais, principalmente na área de saúde.

A NEDP se apresenta como a antítese do neoliberalismo. É sintomático que governos que propõem um modelo econômico que reduza as capacidades estatais estão tendo maiores dificuldades no manejo da crise provocada pelo coronavírus, que se apresenta como "uma externalidade não-prevista, afetando qualquer modelo de expectativa racional ou de Estado-mínimo" (UEBEL, 2020). Logo, conclui-se que a economia neoliberal é deficitária em gerenciar problemas complexos, não possuindo a capacidade material e de planejamento para lidar com crises e pandemias. Desta forma, a originalidade da proposição teórica da NEDP, assim como a atuação enfática das capacidades estatais chinesas no combate à Covid-19, é fundamental nesta reflexão crítica.

\section{REFERÊNCIAS}

AGUIAR, R. B.; LIMA, L. L. Capacidade estatal: definições, dimensões e mensuração. BIB: Revista Brasileira de Informação Bibliográfica em Ciências Sociais, n. 89, p. 1-28, ago. 2019.

BELLUZZO, L. Dinheiro e transfigurações da riqueza. In: TAVARES, M. C.; FIORI, J. L. (Orgs.). Poder e dinheiro: uma economia política da globalização. Petrópolis: Vozes, 1997, p. 151-194.

BICHIR, R. A emergência e a consolidação de programas de transferência de renda no Brasil, na Argentina e na África do Sul. In: GOMIDE, A. A.; BOSCHI, R. (Orgs.). Capacidades estatais em países emergentes: o Brasil em perspectiva comparada. Rio de Janeiro: Instituto de Pesquisa Econômica Aplicada, 2016, p. 325-359.

BRAGA, J. C. Financeirização global: O padrão sistêmico de riqueza do capitalismo contemporâneo. In: TAVARES, M. C.; FIORI, J. L. (Orgs.). Poder e dinheiro: uma economia política da globalização. Petrópolis: Vozes, 1997, p. 195-242

BRESSER-PEREIRA, L. C. Assalto ao Estado e ao mercado, neoliberalismo e teoria econômica. Estudos Avançados, v. 23, n. 66, p. 7-23, 2009.

BRESSER-PEREIRA, L. C.; JABBOUR, E.; PAULA, L. F. South Korea's and China's catching-up: a new-developmentalist analysis. Brazilian Journal of Political Economy, v. 40, n. 2, p. 264-284, 2020.

CARIELLO, T. A pandemia e a política externa chinesa. Carta Brasil-China, v. 25, p. 16-18, abr. 2020.

CASTRO, M. H. Elementos de economia do projetamento. In: HOLANDA, F. M.; ALMADA, J. U. P. S.; PAULA, R. Z. A. Ignacio Rangel: decifrador do Brasil. São Luís: Edufma, 2014.

CEIC. CEIC Data. CEIC: Global Economic Data, Indicators, Charts \& Forecasts, 2020.

CHINA. Ministry of Foreign Affairs of the People's Republic of China. China pledges additional US\$30 million cash contribution to WHO. Beijing: Ministry of Foreign Affairs of the People's Republic of China, 24 Apr. 2020a.

CHINA. Ministry of Foreign Affairs of the People's Republic of China. MFA: China has announced assistance to 82 countries, WHO and African Union to fight Covid-19. Beijing: Ministry of Foreign Affairs of the People's Republic of China, 20 mar. $2020 \mathrm{~b}$. 
CHINA says it has help over 130 countries and intl organizations fight covid-19 pandemic. CGTN - China Global Television Network, 10 apr. 2020c.

CHINA strengthens int'l cooperation in covid-19 vaccine development: official. Beijing, 26 mar. 2020d.

D’ATRI, F. China: efeitos econômicos já conhecidos da Covid-19. Carta Brasil-China, v. 25, p. 19-21, abr. 2020.

FIORI, J. L. Globalização, hegemonia e império. In: TAVARES, M. C.; FIORI, J. L. (Orgs.). Poder e dinheiro: uma economia política da globalização. Petrópolis: Vozes, 1997, p. 87-150.

GABRIELE, A. Enterprises, Industry and Innovation in the People's Republic of China: Questioning Socialism from Deng to the Trade and Tech War. New York: Springer, 2020.

GABRIELE, A.; SCHETTINO, F. Socialist market economy as a distinct Socio-Economic Formation internal to the modern Mode of Production. New Proposals: Journal of Marxism and Interdisciplinary Inquiry, v. 5, n. 2, p. 20-50, 2012.

GUTTMANN, R. Uma introdução ao capitalismo dirigido pelas finanças. Novos Estudos CEBRAP, n. 82, p. 1-33, 2008.

HENDERSON, H. D. Note on the problem of maintaining full employment. In: HENDERSON, H. D. The inter-war years and other essays. Oxford: Oxford University Press, 1951, p. 55-76.

HUI, Z. Batalha ressalta méritos do sistema. China Hoje, v. 5, n. 29, p. 29-32, 2020.

IMF - INTERNATIONAL MONETARY FUND. World economic outlook: the great lockdown. Washington, D.C: IMF, 2020.

JABBOUR, E. China: socialismo e desenvolvimento, sete décadas depois. São Paulo: Anita Garibaldi, 2019.

JABBOUR E.; DANTAS, A. Na China emerge uma Nova Formação Econômico-Social. Princípios, n. 155 , p. $70-86,2018$

JABBOUR, E.; DANTAS, A. Sobre a China e o "socialismo de mercado" como uma nova formação econômico-social. Nova Economia, v. 30, n. 3, p. 1029-1051, 2020.

JABBOUR, E.; DANTAS, A. The political economy of reforms and the present Chinese transition. Brazilian Journal of Political Economy, v. 37, n. 4, p. 789-807, 2017.

JABBOUR, E.; DANTAS, A.; ESPÍNDOLA, J. C; VELLOZO, J. A (Nova) Economia do Projetamento: o conceito e suas novas determinações na China de hoje. Geosul, v. 35, n. 77, p. 17-48, 2020.

JABBOUR, E.; PAULA, L. F. A China e a "socialização do investimento": uma abordagem KeynesGerschenkron-Rangel-Hirschman. Revista de Economia Contemporânea, v. 22, n. 1, p. 1-23, 2018.

JAGUARIBE, A. Capacidades estatais comparadas: China e a reforma do sistema nacional de inovação. In: GOMIDE, A. A.; BOSCHI, R. R. (Orgs.). Capacidades estatais em países emergentes: o Brasil em perspectiva comparada. Rio de Janeiro: Instituto de Pesquisa Econômica Aplicada, 2016, p. 361-386.

JINPING, X. Speech by President Xi Jinping at opening of 73rd World Health Assembly. Global Times, Beijing, 18 May 2020.

KEQIANG, L. Full text: Premier Li's speech at the third session of the 13th NPC. CGTN - China Global Television Network, 22 may 2020. Disponível em: https://news.cgtn.com/news/2020- 
05-22/Full-text-Premier-Li-s-speech-at-the-third-session-of-the-13th-NPC-QHaP1FpB8k/ index.html. Acesso em: 22 maio 2020.

LARDY, N. Markets over Mao: the rise of private business in China. Washington, D.C.: Peterson Institute for International Economics, 2014.

LARDY, N. The state strikes back: the end of economic reform in China? Washington, D.C.: Peterson Institute for International Economics, 2018.

LI, E. Xi Jinping Is a 'Good Emperor'. Foreign Policy, 14 May 2020.

LO, D.; WU, M. The State and industrial policy in Chinese economic development. In: SALAZARXIRINACHS, J. M.; NUBLER, I.; KOZUL-WRIGHT, R. (Eds.). Transforming economies: making industrial policy work for growth, Jobs na development. Geneva: International Labour Office, 2014.

MAJEROWICZ, E. China and the international political economy of information and communication technologies. Textos para Discussão, UFRN, n. 2, 2019.

MAJEROWICZ, E; MEDEIROS, C. A. Chinese industrial policy in the geopolitics of the information age: the case of semiconductors. Revista de Economia Contemporânea,v. 22, n. 1, p. 35-61, 2018.

MEDEIROS, C. A. Apresentação à Conferência Internacional Economia Política da China. In: CONFERÊNCIA INTERNACIONAL - ECONOMIA POLÍTICA DO DESENVOLVIMENTO DA CHINA, 2017, Rio de Janeiro. Anais... Rio de Janeiro: LabChina, 2017. Disponível em: https://www.youtube.com/watch?v=xd7pWVe4bfA\&t=1s. Acesso em: 5 mar. 2020.

MEDEIROS, C. A. Padrões de investimento, mudança institucional e transformação estrutural na economia chinesa. In: BIELSCHOWSKY, R. (Org.). Padrões de desenvolvimento econômico (1950-2008): América Latina, Ásia e Rússia. Brasília, D.F.: CGEE - Centro de Gestão e Estudos Estratégicos, 2013, p. 435-490.

MERINO, G. E. China y el nuevo momento geopolítico mundial. CLACSO - Consejo Latinoamericano de Ciencias Sociales, 2020.

MINSKY, H. P. Stabilizing an unstable economy. New Haven: Yale University Press, 1986.

NBSC - NATIONAL BUREAU OF STATISTICS OF CHINA. Série de dados sobre comércio exterior. State Council of the People's Republic of China, 2020. Disponível em: www.stats. gov.cn. Acesso em: 8 mai. 2020.

NAUGHTON, B. Growing out of the plan: Chinese economic reform, 1978-1993. Cambridge: Cambridge University Press, 1996.

NAUGHTON, B.: Is China socialist? Journal of Economic Perspectives, v. 31, n. 1, p. 3-24, 2017.

NAUGHTON, B. The Chinese Economy: transitions and growth. Cambridge: The MIT Press, 2007.

NAUGHTON, B. TSAI, K. S. (Eds.). State capitalism, institutional adaptation, and the Chinese miracle. Cambridge: Cambridge University Press, 2015.

NOLAN, P. China and the global economy: national champions, industrial policy and the big business revolution. London: Palgrave Macmillan, 2001.

NOGUEIRA, I.; GUIMARÃES, J. V.; BRAGA, J. P. Inequalities and capital accumulation in China. Brazilian Journal of Political Economy, v. 39, n. 3, p. 449-469, 2019. 
PIKETTY, T; YANG, L.; ZUCMAN, G. Capital accumulation, private property and rising inequality in China. NBER Working Paper, n. 23368, Apr. 2017.

PLA shares experience in Covid-19 fight with militaries from multiple countries. Beijing 16 may 2020.

RANGEL, I. Elementos de economia do projetamento. In: RANGEL, I.: Obras reunidas. Rio de Janeiro: Contraponto, 2005a. Vol. 1.

RANGEL, I. Recursos ociosos e política econômica. In: RANGEL, I.: Obras reunidas. Rio de Janeiro: Contraponto, 2005b. Vol. 2.

RIBEIRO, V. L.; PARANÁ, E. Virtú e fortuna: A trajetória da ação desenvolvimentista chinesa e seus desafios contemporâneos. Revista da Sociedade Brasileira de Economia Política, N. 54, 2019.

SKOCPOL, T. Bring the state back in: strategies of analysis in current research. In: EVANS, P.; RUESCHEMEYER, D.; SKOCPOL, T. (Orgs.). Bringing the state back in. Cambridge: Cambridge University Press, 1985, p. 3-38.

STATE COUNCIL OF PEOPLE'S REPUBLIC OF CHINA. 'Made in China 2025' plan issued. Disponível em: http://english.www.gov.cn/policies/latest_releases/2015/05/19/ content_281475110703534.htm. Acessado 18 maio 2020

TRUMP, D. This is the letter sent to Dr. Tedros of the World Health Organization. It is selfexplanatory! Washington, 18 maio 2020. Twitter: @realDonaldTrump. Disponível em: https:// twitter.com/realdonaldtrump. Acesso em: 19 maio 2020.

UEBEL, R. R. G. A geopolítica do coronavírus em tempos de incertezas. Revista Diálogos Internacionais, v. 7, n. 70, 6 abr. 2020.

WANMING, Y. Criar uma aldeia global de saúde e segurança e construir uma comunidade de futuro compartilhado. China Hoje, v. 5, n. 29, p. 66, 2020.

WEN, X. Esforços incansáveis para conter o vírus. China Hoje, v. 5, n. 29, p. 18-21, 2020.

WHO - WORLD HEALTH ORGANIZATION. Covid-19: Q\&A with Dr Galea. Geneva: WHO, 2020a.

WHO - WORLD HEALTH ORGANIZATION. Report of the WHO-China joint mission on coronavirus disease 2019 (Covid-19). Geneva: Joint Mission On Coronavirus Disease 2019, 2020b.

WHO - WORLD HEALTH ORGANIZATION. WHO Coronavirus (COVID-19) Dashboard. WHO, 2020c. Disponível em: https://covid19.who.int/. Acesso em: 30 maio 2020.

XI emphasizes 'struggles' to achieve national rejuvenation. Beijing, 3 September 2019.

WORLD BANK DATA. Gross capital formation. [On-line] The World Bank Data, 2021. Disponível em: https://data.worldbank.org/indicator/NE.GDI.TOTL.ZS. Acesso em: 28 maio 2020 